\title{
Protocol
}

\section{Rapid quantification and neutralization assays for novel coronavirus SARS-CoV-2 using Avicel ${ }^{\circledR}$ RC-591 semi-solid overlay}

\author{
Anna N. Honko 1,*®0000-0001-9165-148X, Nadia Storm 1,@0000-0002-2596-0468, David J. Bean \\ 1, 0000-0001-7497-8026, Jhonatan Henao Vasquez 1, D0000-0003-3129-2774, Sierra N. Downs \\ 1, D0000-0002-9954-3237 and Anthony Griffiths 1, (D000-0001-5435-8364 \\ 1 Department of Microbiology and National Emerging Infectious Diseases Laboratories, Boston University \\ School of Medicine, Boston, MA, USA; honko@bu.edu (A.N.H.); nstorm@bu.edu (N.S.); djbean@bu.edu \\ (D.J.B.); jhenao@bu.edu (J.H.V.); snd@bu.edu (S.N.D.); ahgriff@bu.edu (A.G.) \\ * Correspondence: honko@bu.edu; Tel.: (+1-617-358-9284)
}

\begin{abstract}
When working with the novel coronavirus SARS-CoV-2 during a pandemic response, having a rapid, reproducible and reliable assay for infectious virus quantitation and utilization for evaluation of potential therapeutics is critical. Compared to traditional agarose overlay plaques visualized with neutral red, assays performed with Avicel ${ }^{\circledR}$ RC-591 semi-solid overlay provide a simplified format for rapid and easy detection and neutralization testing. The method is easily modified for higher throughput using dispensers or automated processing. Fixation using formalin provides flexibility when dealing with pathogenic agents such as SARS-CoV-2 where tissue culture plates might be removed from biocontainment for staining. Although plaque assays are considered straightforward in principle, having an easily reproducible, consistent plaque assay is an invaluable tool.
\end{abstract}

Keywords: plaque assay; neutralization; SARS; SARS-CoV-2; coronavirus; Avicel; methylcellulose; COVID

\section{Introduction}

Severe acute respiratory syndrome coronavirus 2 (SARS-CoV-2) belongs to the family Coronaviridae and is the cause of the unprecedented and ongoing coronavirus disease 2019 (COVID-19) pandemic, which to date has infected more than 4 million people and caused over 300,000 deaths worldwide.[1] There is an urgent need for reliable, cost-effective and rapid assays to screen antibodies and other therapeutic compounds for neutralization activity against SARS-CoV-2.

Recently, a number of neutralization assays for SARS-CoV-2 have been reported using pseudotyped viruses[2,3] which are easier to manipulate at lower biosafety levels and allow the interrogation of specific receptor/Spike protein interactions by researchers. However, as they are specific clones these do not account for diversity of the virus that is seen in an authentic virus. Additionally, these systems do not account for interactions with any viral protein other than Spike or any step other than blocking of receptor binding, thus limiting their use. Another method for examining neutralization of serum or therapeutic compounds is a microneutralization assay based on $50 \%$ cell culture infectious dose $\left(\mathrm{TCID}_{50}\right)$ endpoint dilution assay. This uses live SARS-CoV-2 and relies on the cytopathic effect (CPE) caused by the virus.[4] However, this assay takes 3 to 4 days so more rapid alternatives are sought.

The plaque assay is the classic method for detection and quantitation of cytopathic or lytic viruses, frequently considered a gold standard for determining the concentration of live virus in a sample. Cells are grown in a monolayer and infected at various dilutions of virus, followed by an overlay. The solid or semi-solid overlay limits the viral spread to a localized region of the monolayer and following infection, this localized cell death will result in a plaque visualized after staining with crystal 
violet or neutral red as a relatively clear area. There are several disadvantages to traditional solid agarose overlays that many researchers encounter, mainly surrounding the requirement to maintain the agarose at an appropriate temperature above melting that is warm enough not to solidify and clump, but not so warm as to cause damage to the cell monolayer. Clumps or bubbles in the overlay can obfuscate plaques, as will flakes or precipitation of the neutral red if used for staining. Often agarose-overlaid plates are not fixed, forcing the user into a timeline for reading and counting the plaques that may be inconvenient and not as easily suited for high-throughput or to have a second analyst verifying counts.

Many of these difficulties are overcome by use of a semi-solid overlay. Methylcellulose overlays have many advantages, but have a high viscosity making them more difficult to prepare and handle. The use of Avicel ${ }^{\circledR}$ overlays as an alternative to methylcellulose for viral plaque assays was previously described for influenza virus[5] and the coronavirus NL63[6], as well as for hemorrhagic fever viruses in biocontainment settings, including filoviruses (Ebola virus and Marburg virus[7-9]), arenaviruses and paramyxoviruses (Nipah virus[10]). Avicel ${ }^{\circledR}$ RC-591 is a dispersible co-processed blend of microcrystalline methylcellulose and sodium carboxymethylcellulose used for colloidal formulations with pharmaceutical and cosmetic applications, including lotions, creams, sunscreen, nasal sprays, and oral drug suspensions.[11] It has an extended shelf-life and is stable at ambient temperatures following autoclave sterilization procedures. In this paper we have detailed the use of Avicel ${ }^{\circledR}$ RC-591 as a low-viscosity, semi-solid overlay for plaque assays for SARS-CoV-2 detection, quantitation and plaque reduction neutralization assay.

\section{Results}

A series of plaque assays were performed in order to establish the conditions for plaquing SARS-CoV-2 using the Avicel $\mathbb{R}$ RC-591 semi-solid overlay. Confluent monolayers of VeroE6 cells were used in 6-well plates at one-day post-seeding, and assays were performed in triplicate using $200 \mu \mathrm{L}$ inoculum volumes and $2 \mathrm{~mL}$ of $1 \mathrm{X}$ overlay without removing the inoculum. Fixing and staining two-days post-infection produced distinct, clearly countable plaques (Figure 1a). Plaques were not easily distinguishable by eye at one-day post-infection (data not shown). For ease of counting and traceability purposes, plates were scanned and counted using Adobe Photoshop, as shown in the example in Figure $1 b$.
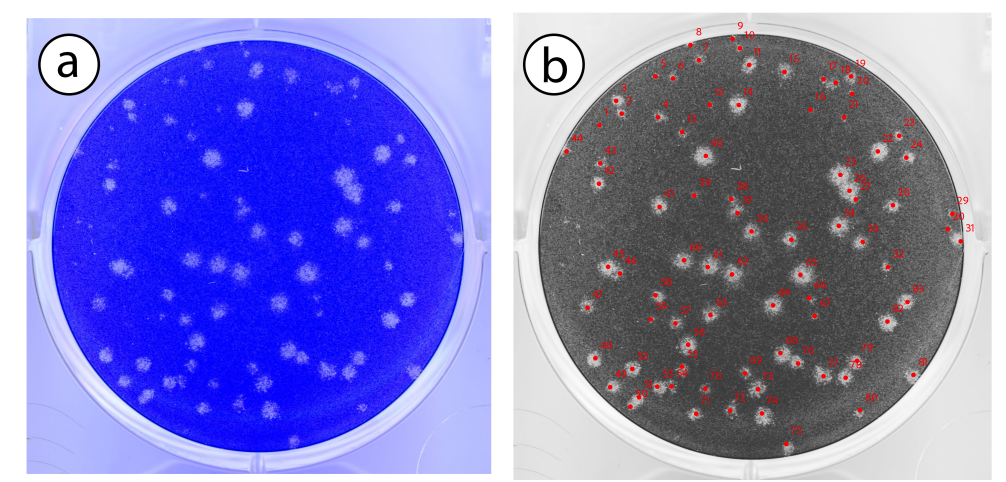

Figure 1. Representative well from SARS-CoV-2 Avicel ${ }^{\circledR}$ RC-591 plaque assay. (a) Following crystal violet staining, plaques can be visualized and enumerated using a light box. (b) Scans in greyscale can be processed for counting using software (shown here is Adobe Photoshop v21.1.0 Count Tool).

To ensure that the assay could be performed and analyzed by multiple individuals for therapeutic screening, an experiment was conducted in which an analyst performed a plaque reduction neutralization test in triplicate and plaqued in triplicate. All of the samples from this experiment were counted by the analyst who performed the assay, as well as two independent analysts. Although there was some variability between the exact counts of the analysts (Figure 2a), each analyst trended 
similarly, indicating internal consistency surrounding counting methodology. Most importantly, when the counts from each individual were used to calculate the plaque reduction and compared to the mean plaque reduction, they were similar (Figure $2 b$ ). This result demonstrates that the variation in individual counts is accounted for by the calculation of the reduction and the overall result of the experiment should not be significantly impacted.
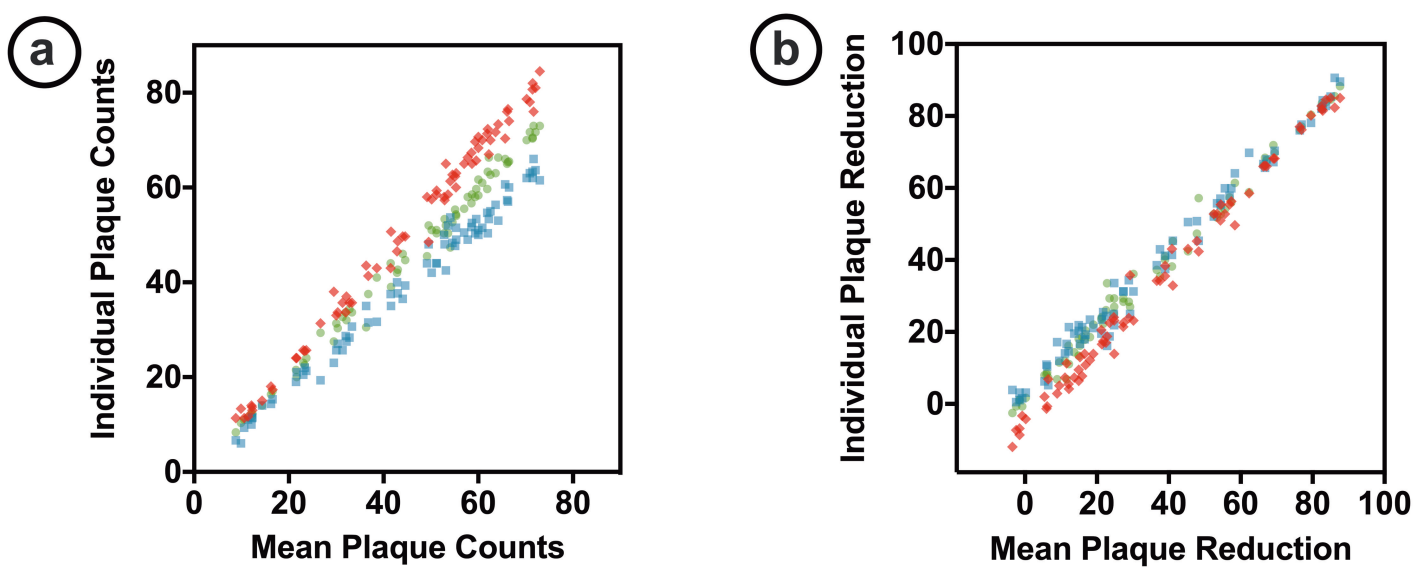

Figure 2. Consistency of plaque counts between multiple analysts (a) Three analysts independently counted 72 samples and the individual counts were plotted against the mean of the three analysts. Each analyst was internally consistent with counts with low variability in counts (average \%CV of 13.04). (b) When individual counts were used for calculations of plaque reduction and compared to the mean the results correlated well, indicating that effects of individual analysts should not impact the overall result of the experiment.

\section{Discussion}

Avicel ${ }^{\circledR}$ RC-591 solutions have the advantage of being simple to prepare and use, without requiring additional heating and have extended shelf-stability (similar effectiveness has been shown with other viruses up to 2 years post-preparation). The low-viscosity of the overlay and ambient stability lends towards assay optimization and automation. The assay format is easily adapted for high-throughput therapeutic screens or serum neutralization assays, with the potential to adapt to 12-or 24-well plates for higher throughput screening which would allow for use of smaller sample volumes and multiple replicates for increased statistical significance. This overlay can also be adapted to methods that use immunological detection and further optimize scale, such as immunoplaque methods that are modifiable to a 96-well format.[5]

There are gains in flexibility of assay set-up as well as with staining and enumeration, as the user has several options: stain rapidly for immediate counting, stain directly through the overlay for convenience, or fixation of the plates in $10 \%$ neutral buffered formalin for removal from containment. Because the plates are fixed and stained, plaque visibility is maintained after drying, allowing for flexibility in counting, as well as verification of counts by other analysts if enhanced data integrity is requested. This assay flexibility allows en masse preparation of plaque reduction assays and analysis of data over several days. In addition, establishment of an imaging system and coordination with automated counting software would further reduce analyst subjectivity, for example the Immunospot ${ }^{\circledR}$ S6 analyzer with BioSpot ${ }^{\circledR}$ software (Cellular Technology Limited, Cleveland, OH) can be used for scanning and plaque counting.

We recommend Avicel ${ }^{\circledR}$ RC-591 or other semi-solid overlays as a rapid, easy and reproducible format for plaque-based assays using SARS-CoV-2. 


\section{Materials and Methods}

\subsection{Preparation of reagents}

\subsubsection{Media}

All media are stored at $4^{\circ} \mathrm{C}$ for 6 months or until earliest expiration date of constituent components.

- Cell growth medium is Dulbecco's modified Eagle medium (DMEM) with GlutaMAXTM and sodium pyruvate (Gibco ${ }^{\mathrm{TM}}$, ThermoFisher Scientific, Waltham, MA, catalog 10569) supplemented to $10 \%(\mathrm{v} / \mathrm{v})$ certified US-origin heat-inactivated fetal bovine serum (HI-FBS, Gibco ${ }^{\mathrm{TM}}$, catalog 10082).

- Plaque Assay Dilution Medium is DMEM with GlutaMAX ${ }^{\mathrm{TM}}$ and sodium pyruvate $\left(\mathrm{Gibco}^{\mathrm{TM}}\right.$, catalog 10569), supplemented to $2 \%$ (v/v) HI-FBS (Gibco ${ }^{\mathrm{TM}}$, catalog 10082) and $1 \mathrm{X}$ Antibiotic-Antimycotic (Gibco ${ }^{\mathrm{TM}}$, catalog 15240).

- For overlays, a 2X Plaque Assay Medium was prepared using 2X Modified Eagle Medium (Temin's modification, Gibco $^{\mathrm{TM}}$, catalog 11935) supplemented with 2X Antibiotic-Antimycotic $\left(\right.$ Gibco $\left.^{\mathrm{TM}}\right), 2 X$ GlutaMAX (Gibco ${ }^{\mathrm{TM}}$, catalog 35050) and 10\% (v/v) HI-FBS (Gibco $\left.{ }^{\mathrm{TM}}\right)$.

\subsubsection{Avicel $R$ RC-591 2X solution for overlay}

The Avicel ${ }^{\circledR}$ RC-591 microcrystalline cellulose and carboxymethylcellulose sodium used for our studies was provided by DuPont Nutrition \& Biosciences (Wilmington, DE) and no additional reagents or sources were compared for these studies. However, other researchers have provided information regarding commercially available microcrystalline cellulose products and these may be useful for laboratory use.[12]

2 X Avicel ${ }^{\circledR}$ RC-591 solution is prepared by adding Avicel ${ }^{\circledR}$ RC-591 to distilled water to a final concentration of $2.5 \%$ Avicel ${ }^{\circledR}$ RC-591 (w/v). For example, add $12.5 \mathrm{~g}$ of Avicel ${ }^{\circledR}$ RC-591 per $1 \mathrm{~L}$ bottle autoclavable bottle (glass not preferred, Corning Lexan-style bottles are ideal) and QS to 500mL with distilled water (Gibco ${ }^{\mathrm{TM}}$ 15230). Place a magnetic stir bar into the bottle and shake gently over time until homogeneous. Solution should appear as a smooth, milky liquid with no visible clumps. The solution should be autoclaved using a 15-30 minute liquid cycle and batched pooled as required in a biosafety cabinet after cool. The Avicel ${ }^{\circledR}$ RC-591 solution is stored at ambient temperature and is stable for at least 2 years from the date of preparation. Discard the Avicel ${ }^{\circledR}$ RC-591 solution if it becomes cloudy or appears contaminated.

\subsubsection{Staining solution}

A solution of $0.2 \%$ crystal violet and $10 \%$ formalin is prepared by mixing $100 \mathrm{~mL} 2 \%$ aqueous Gentian Violet (RICCA Chemical Company, Arlington, TX, catalog 3233-16) with 500mL 20\% neutral buffered formalin (Richard-Allan Scientific ${ }^{\mathrm{TM}}$, Fisher Scientific, catalog 23-751800) and QS'ing to $1 \mathrm{~L}$ with distilled water.

\subsection{Cells and virus}

The virus stock used for these studies had been passaged three times in VERO cells and twice in VeroE6 cells and has been designated as lot NSU-V004. SARS-CoV-2 USA-WA1/2020 [13] was propagated in Vero E6 cells (BEI resources, NIAID, NIH: VERO C1008 (E6), African green monkey kidney, Working Bank \# NR-596) in DMEM (Gibco ${ }^{\mathrm{TM}}$, catalog 11960) supplemented with GlutaMAX ${ }^{\mathrm{TM}}$ (Gibco $^{\mathrm{TM}}$, catalog 35050), sodium pyruvate $\left(\mathrm{Gibco}^{\mathrm{TM}}\right.$, catalog 11360), Non-essential Amino Acids (NEAA, Gibco $^{\mathrm{TM}}$, catalog 11140), Antibiotic-Antimycotic (Gibco ${ }^{\mathrm{TM}}$, catalog 15240) and 2\% HI-FBS, Gibco $^{\mathrm{TM}}$, catalog 10082). At 66 hr post-inoculuation, the supernatant was clarified by centrifugation and the concentration of HI-FBS was QS'd to $10 \%$ final concentration. All procedures performed with the virus were conducted in a Biosafety level 4 (BSL4) laboratory. 


\subsection{Detailed plaque assay protocol}

1. Plate Vero E6 cells at $6-8 \times 10^{5}$ per well in 6 well plates (Corning ${ }^{\circledR}$ CellBIND catalog 3335) to achieve confluency the next day.

2. Serially dilute samples in Plaque Assay Dilution Medium.

3. Decant, aspirate or pipette growth medium from 1-2 plates at a time and add $200 \mu \mathrm{L}$ of diluted samples to appropriate wells in triplicate.

4. Adsorb samples to the cell monolayers for $1 \mathrm{~h}$ at $37^{\circ} \mathrm{C}$ and $5 \% \mathrm{CO} 2$ with gentle rocking approximately every 15 minutes to prevent monolayer drying. For a large number of plates, it is necessary to incubate and rock in groups.

5. Pre-warm $2 X$ Plaque Assay Medium and $2 X$ Avicel ${ }^{\circledR} R C-591$ solution to $37^{\circ} \mathrm{C}$ in a waterbath or an electronic bead bath. Prepare the overlay by combining Avicel ${ }^{\circledR}$ RC-591 $2 X$ Overlay and 2X Plaque Assay Media 1:1 to obtain a 1X concentration and mixing well by inversion. The 1X mixture should not be stored for extended periods.

6. Without removal of the inoculum, overlay the monolayers with $2 \mathrm{~mL}$ per well of a 1:1 mix of $2.5 \%$ Avicel ${ }^{\circledR}$ RC-591 solution mixed with 2X Plaque Assay Medium using a serological pipette or dispensing pipettor (ex. Eppendorf ${ }^{\circledR}$ Repeater ${ }^{\circledR} /$ Combitips advanced ${ }^{\circledR}$ system).

7. Swirl plates gently to mix and incubate at $37^{\circ} \mathrm{C}$ and $5 \% \mathrm{CO} 2$ for 2 days.

8. Gently swirl plates to loosen the Avicel ${ }^{\circledR}$ RC-591 and discard the overlay to waste. Fix plates with $10 \%$ neutral buffered formalin before removing from containment, then stain with $0.2 \%$ crystal violet staining solution for 30 minutes. Rinse under tap water and dry prior to enumeration.

\subsection{Detailed plaque reduction neutralization assay}

1. Plate Vero E6 cells at $6-8 \times 10^{5}$ per well in 6 well plates (Corning ${ }^{\circledR}$ CellBIND catalog 3335) to achieve confluency the next day.

2. Serially dilute therapeutic test article (TA) in a 96-well polypropylene deepwell plate (Nunc, catalog 278743). Polystyrene or tissue-culture treated plates are avoided as antibodies may adsorb tightly. Ensure that negative control and if possible, known positive controls are included. Example dilution series included:

(a) Two-fold dilutions:

i. Start with $650 \mu \mathrm{L}$ of TA at highest concentration in first well and $325 \mu \mathrm{L}$ of Vehicle (TA resuspension buffer, or PBS, as appropriate) in remaining wells.

ii. Serially dilute $325 \mu \mathrm{L}$, mixing at least 5 times (gently, avoiding air bubbles) at each step.

iii. Change pipette tips and transfer to next well.

iv. Discard final $325 \mu \mathrm{L} .325 \mu \mathrm{L}$ should remain in each well.

(b) Log dilutions:

i. Start with $360 \mu \mathrm{L}$ of TA in first well and $324 \mu \mathrm{L}$ of Vehicle in remaining wells

ii. Serially dilute $36 \mu \mathrm{L}$, mixing at least 5 times (gently, avoiding air bubbles) at each step.

iii. Change pipette tips and transfer to next well.

iv. Discard final $36 \mu \mathrm{L} .324 \mu \mathrm{L}$ should remain in each well.

(c) Half-log dilutions:

i. Start with $475 \mu \mathrm{L}$ of TA in first well and $325 \mu \mathrm{L}$ of Vehicle in remaining wells.

ii. Serially dilute $150 \mu \mathrm{L}$, mixing at least 5 times (gently, avoiding air bubbles) at each step.

iii. Change pipette tips and transfer to next well.

iv. Discard final $150 \mu \mathrm{L} .325 \mu \mathrm{L}$ should remain in each well.

(d) Quarter-log dilutions:

i. Start with $800 \mu \mathrm{L}$ of TA in first well and $350 \mu \mathrm{L}$ of Vehicle in remaining wells.

ii. Serially dilute $450 \mu \mathrm{L}$, mixing at least 5 times (gently, avoiding air bubbles) at each step.

iii. Change pipette tips and transfer to next well. 
iv. Discard final $450 \mu \mathrm{L} .350 \mu \mathrm{L}$ should remain in each well.

3. Seal plates with sterile, breathable plate sealer for transfer to biocontainment (CELLTREAT scientific products, catalog 229130).

4. Dilute virus in DMEM Plaque assay diluent to a concentration of 100 PFU per well for 6 well plate $\left(1 \times 10^{3} \mathrm{PFU} / \mathrm{mL}\right.$, as $200 \mu \mathrm{L}$ is used for assay) sufficient for number of samples.

5. Using a multichannel pipette, mix diluted virus 1:1 with diluted TA in the deepwell plate (either $325 \mu \mathrm{L}$ or $350 \mu \mathrm{L}$ added per well, depending on dilution series). For calculation purposes, at least one set of samples were included that were diluent + virus only.

6. Seal deepwell plates with a fresh sterile, breathable plate sealer and incubate at $37^{\circ} \mathrm{C}$ for $60 \pm 10$ minutes.

7. Following this incubation, remove all media from the 6-well plates by pipetting, aspiration or decanting and add $200 \mu \mathrm{L}$ of each dilution to the appropriate wells in triplicate. Mock-infected wells are included as negative control.

8. Incubate plates at $37 \pm 4^{\circ} \mathrm{C}, 5 \pm 1 \% \mathrm{CO}_{2}$ for $60 \pm 10$ minutes, rocking gently approximately every $10 \pm 5$ minutes, and overlay with $2 \mathrm{~mL}$ of $1: 1$ mixture of Avicel ${ }^{\circledR}$ RC-591 $2 X$ Overlay and $2 \mathrm{X}$ Plaque Assay Media as in plaque assay method.

9. Following 2 day incubation at $37^{\circ} \mathrm{C}$ and $5 \% \mathrm{CO}_{2}$, plates are fixed, removed from biocontainment, stained and counted.

10. To determine the $\mathrm{IC}_{50}$ values in GraphPad Prism v.8.4.2 software, from an XY data table of percent reduction on the $\mathrm{Y}$ axis (using the diluent + virus-only control set to $100 \%$ ) versus the logarithm of the concentration of the inhibitor ( $\mathrm{X}$ axis) use the nonlinear regression analysis, "Dose-response curves - Inhibition" “log(inhibitor) vs. response." The $\mathrm{IC}_{50}$ is the concentration of agonist that gives a response half way between Bottom and Top (where Top and Bottom are plateaus in the units of the $Y$ axis). This is not necessarily the same as the response at $Y=50$, and the values of Bottom and Top, the $\mathrm{IC}_{50}$ may give a response nowhere near "50". Prism reports both the $\mathrm{IC}_{50}$ and its $\log$.

Note: Final compound concentrations in assay wells are twofold less than that in the compound dilution plate due to the addition of virus during incubation step.

Author Contributions: Conceptualization, A.N.H. and A.G.; methodology, A.N.H.; formal analysis, A.N.H.; investigation, A.N.H., N.S., S.N.D., D.J.B, J.H.V.; data curation, A.N.H.; writing-original draft preparation, A.N.H., N.S.; writing-review and editing, all authors; visualization, A.N.H.; supervision, A.N.H.; project administration, S.N.D.; funding acquisition, A.G.

Funding: This research received no external funding.

\section{Acknowledgments:}

The Avicel ${ }^{\circledR}$ RC-591 for these efforts was generously provided by DuPont Nutrition \& Biosciences, Wilmington, Delaware. The following reagent was obtained through BEI Resources, NIAID, NIH: VERO C1008 (E6), Kidney (African green monkey), Working Cell Bank, NR-596. The SARS-CoV-2 starting material was provided by the World Reference Center for Emerging Viruses and Arboviruses (WRCEVA), with Natalie Thornburg (nax3@cdc.gov) as the CDC Principal Investigator.

Conflicts of Interest: The authors declare no conflict of interest.

\section{Abbreviations}

The following abbreviations are used in this manuscript: 


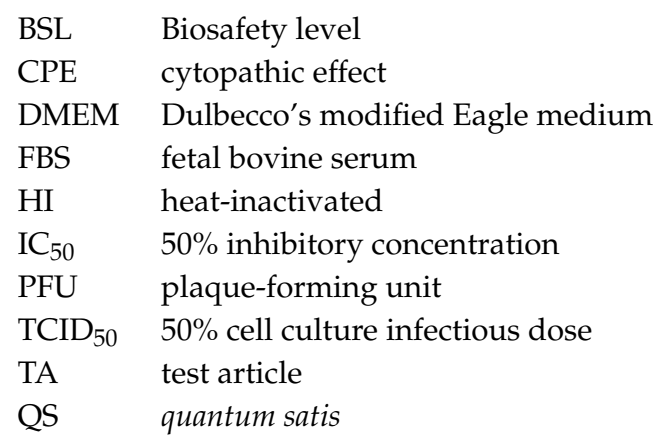

\section{References}

1. World Health Organization (2020). Situation Report 114 - Coronavirus disease 2019 (COVID-19) 13 May 2020. Available online: https://www.who.int/emergencies/diseases/novel-coronavirus-2019/situation-reports. accessed on 14 May 2020

2. Crawford KHD, Eguia R, Dingens AS, Loes AN, Malone KD, Wolf CR, Chu HY, Tortorici MA, Veesler D, Murphy M, Pettie D, King NP, Balazs AB, Bloom JD. Protocol and Reagents for Pseudotyping Lentiviral Particles with SARS-CoV-2 Spike Protein for Neutralization Assays. Viruses. 2020 6:12, pii: E513.

3. Nie J, Li Q, Wu J, Zhao C, Hao H, Liu H, Zhang L, Nie L, Qin H, Wang M, Lu Q, Li X, Sun Q, Liu J, Fan C, Huang W, Xu M, Wang Y. Establishment and validation of a pseudovirus neutralization assay for SARS-CoV-2. Emerg. Microbes Infect. 2020 1, pp: 680-686.

4. Manenti A, Maggetti M, Casa E, Martinuzzi D, Torelli A, Trombetta CM, Marchi S, Montomoli E. Evaluation of SARS-CoV-2 neutralizing antibodies using of a CPE-based Colorimetric live virus micro-neutralization assay in human serum samples. J. Med. Virol. 2020

5. Matrosovich M, Matrosovich T, Garten W, Klenk H-D. New low-viscosity overlay medium for viral plaque assays. Virol. J. 2006 3:63

6. Herzog P, Drosten C, Müller MA. Plaque assay for human coronavirus NL63 using human colon carcinoma cells. Virol. J. 2008 5:138

7. Twenhafel NA, Mattix ME, Johnson JC, Robinson CG, Pratt WD, Cashman KA, Wahl-Jensen V, Terry C, Olinger GG, Hensley LE, Honko AN. Pathology of experimental aerosol Zaire ebolavirus infection in rhesus macaques. Vet. Pathol. 2013 50(3), pp. 514-29.

8. Honko AN, Johnson JC, Marchand JS, Huzella L, Adams RD, Oberlander N, Torzewski LM, Bennett RS, Hensley LE, Jahrling PB, Olinger GG. High dose sertraline monotherapy fails to protect rhesus macaques from lethal challenge with Ebola virus Makona. Sci. Rep. 2017 19;7(1), 5886.

9. Lin KL, Twenhafel NA, Connor JH, Cashman KA, Shamblin JD, Donnelly GC, Esham HL, Wlazlowski CB, Johnson JC, Honko AN, Botto MA, Yen J, Hensley LE, Goff AJ. Temporal characterization of Marburg Virus Angola infection following aerosol challenge in rhesus macaques. J. Virol. 2015 89(19), pp. 9875-85.

10. Johnston SC, Briese T, Bell TM, Pratt WD, Shamblin JD, Esham HL, Donnelly GC, Johnson JC, Hensley LE, Lipkin WI, Honko AN. Detailed analysis of the African green monkey model of Nipah virus disease. PLoS One 2015 10(2), e0117817.

11. Zhao GH, Kapur N, Carlin B, Selinger E, Guthrie JT. Characterization of the interactive properties of microcrystalline cellulose-carboxymethyl cellulose hydrogels. Int. J. Pharm. 2011 415 95-101

12. Matrosovich M. ResearchGate posting: Commercial sources of "Avicel RC/CL" and its analogues for viral plaque assays. Addendum to the article Matrosovich et al. "New low-viscosity overlay medium for viral plaque assays" Virology Journal, Vol3, issue 1, 2006. Available online: https:/ / www.researchgate.net/publication/335543113. accessed on 01 May 2020

13. Harcourt J, Tamin A, Lu X, Kamili S, Sakthivel SK, Murray J, Queen K, Tao Y, Paden CR, Zhang J, Li Y, Uehara A, Wang H, Goldsmith C, Bullock HA, Wang L, Whitaker B, Lynch B, Gautam R, Schindewolf C, Lokugamage KG, Scharton D, Plante JA, Mirchandani D, Widen SG, Narayanan K, Makino S, Ksiazek TG, Plante KS, Weaver SC, Lindstrom S, Tong S, Menachery VD, Thornburg NJ. Severe Acute Respiratory Syndrome Coronavirus 2 from patient with 2019 novel coronavirus disease, United States. Emerg. Infect. Dis. 2020 26(6) 